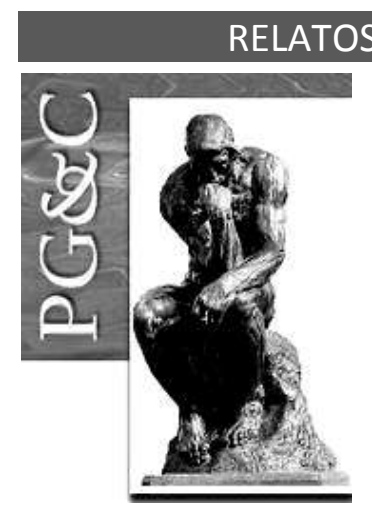

\title{
AS PARCERIAS ENTRE A ADMINISTRAÇÃO PÚBLICA E ASSOCIAÇÕES DA ÁREA DA SAÚDE
}

\author{
Lúcio José Rangel \\ Mestre em Gestão e Desenvolvimento Regional pela Universidade de \\ Taubaté, Brasil. Professor da Faculdade Canção Nova, Brasil. \\ E-mail: lirangel@uol.com.br \\ Lourival da Cruz Galvão Júnior \\ Doutor em Ciências da Comunicação pela Universidade de São Paulo, \\ Brasil. Professor da Universidade de Taubaté, Brasil. \\ E-mail: galvaojr@uol.com.br \\ Moacir José dos Santos \\ Doutor em História pela Universidade Estadual Paulista Júlio de Mesquita \\ Filho, Brasil. Professor da Universidade de Taubaté, Brasil. \\ E-mail: professormoacirsantos@gmail.com
}

\begin{abstract}
Resumo
O Terceiro Setor depara-se atualmente com inovações legislativas e exigências relacionadas às parcerias com a administração pública oriundas do marco regulatório das organizações da sociedade civil. $O$ fato norteia este trabalho, que analisa os elementos de gestão e de marco regulatório em parcerias entre três associações da área da saúde da Região Metropolitana do Vale do Paraíba e Litoral Norte com a administração pública, visando verificar a contribuição dessa sinergia para o desenvolvimento regional. A metodologia segue abordagem qualitativa exploratória, procedimento documental, estudo de multicasos e entrevistas semiestruturadas. Os documentos foram selecionados a partir da sua representatividade para a estruturação do terceiro setor. Os resultados das entrevistas foram analisados sob o método reflexivo e comparados com as exigências pertinentes às mudanças efetuadas no marco regulatório. O estudo evidenciou que as organizações de Terceiro Setor revelam gestão administrativa estruturada, mas especificidades advindas do marco regulatório geram entraves relacionados à administração pública. Observou-se, ainda, nas parcerias elementos da gestão administrativa nas entidades pesquisadas, que contribuem para o desenvolvimento regional por serem empregadoras e prestadoras de serviços em saúde e por manterem laços com a sociedade civil.
\end{abstract}

Palavras-chave: Parcerias. Terceiro Setor. Gestão e Desenvolvimento Regional.

\section{ANALYSIS OF PARTNERSHIPS BETWEEN THE PUBLIC ADMINISTRATION AND HEALTH AREA ASSOCIATIONS}

\begin{abstract}
The Third Sector is currently faced with legislative innovations and requirements related to partnerships with public administration stemming from the regulatory framework of civil society organizations. This fact guides this work, which analyzes the elements of management and regulatory framework in partnerships between three associations of the health area of the Metropolitan Region of Vale do Paraiba and Litoral Norte with the public administration, aiming to verify the contribution of this synergy for Regional Development. The methodology follows a qualitative exploratory approach, documentary procedure, multisite study and semi-structured interviews. The study showed that Third Sector organizations reveal structured administrative management, but specifics arising from the regulatory framework generate obstacles related to public administration. It was also observed in the partnerships
\end{abstract}

Perspectivas em Gestão \& Conhecimento, João Pessoa, v. 9, n. 3, p. 47-63, set./dez. 2019. DOI: http://dx.doi.org/10.21714/2236-417X2019v9n3p47

http://periodicos.ufpb.br/ojs2/index.php/pgc. ISSN: 2236-417X. Publicação sob Licença (cc) EY-NC-ND 
elements of administrative management in the entities surveyed, which contribute to regional development by being employers and providers of health services and by maintaining ties with civil society.

Keywords: Partnerships. ThirdSector. Management and Regional Development.

\section{INTRODUÇÃO}

No passado, a ordem sociopolítica era compreendida por dois setores: o Estado, por intermédio da administração configurada na figura do ente público; e a sociedade, com destaque ao mercado, as iniciativas populares e os indivíduos, representados como entes privados. O Terceiro Setor é composto por organizações privadas, sem fins lucrativos e com atributos públicos (PAES, 1999). Mesmo que recente, mais precisamente na década de 1980, o debate acadêmico e conceitual deflagrado sobre o Terceiro Setor e, em especial nos países em desenvolvimento, atingiu densidade significativa e estabeleceu um campo de pesquisa singular com novas possibilidades de recorte temático e com características próprias (ALBUQUERQUE, 2006).

Conforme Violin (2010), a expressão "Terceiro Setor" é oriunda dos Estados Unidos (década de 1970), NGO - Non-governmental organizations, e existem questionamentos sobre a utilização deste termo; há doutrina afirmando que se existe um Setor que se encontra entre o Primeiro (Estado) e o Segundo (mercado), sendo que este não seria um Terceiro Setor. Mas a referida utilização americana foi condecorada internacionalmente, por meio da Carta das Nações Unidas, confeccionada nos Estados Unidos, no ano de 1945 (VIOLIN, 2010).

O Terceiro Setor é configurado como um mercado social por ocupar-se de atividades não efetivadas, principalmente pelo primeiro setor (TACHIZAWA, 2012). O Terceiro Setor contribui, por intermédio de suas organizações, para a melhoria da qualidade de vida e de participação da sociedade e propicia, por consequência, o Desenvolvimento Regional (SOUZA; THEIS, 2009). Neste âmbito enquadra-se a Região Metropolitana do Vale do Paraíba e Litoral Norte (RMVPLN) que, pela Lei Estadual de São Paulo n.o 1.166/2012, tem entre seus objetivos a redução das desigualdades sociais e o planejamento regional para o desenvolvimento socioeconômico e a melhoria da qualidade de vida. Promulgada pela Presidência da República, a Lei Federal n.o 13.019, de 31 de julho de 2014, conhecida como "Marco Regulatório do Terceiro Setor e das Organizações da Sociedade Civil", soma-se à legislação paulista ao estabelecer o regime jurídico das parcerias entre a administração pública e as organizações da sociedade civil a partir de um regime de mútua cooperação para a consecução de finalidades de interesse público e recíproco (BRASIL, 2014).

Assim sendo, observa-se como imprescindível às entidades de Terceiro Setor da citada região metropolitana compreender e se adaptar às exigências legais de forma rápida e menos impactante possível. Essa urgência justifica-se pelo fato de as entidades, na maioria das vezes, suprirem as atuações estatais sendo, portanto, urgente a adequação legal para que continuem atendendo a contento ao público beneficiário, contribuindo para o Desenvolvimento Regional. O marco regulatório apresenta exigências quanto a atuação das entidades do Terceiro Setor, especialmente para a adequação da gestão e das ações as determinais da legislação. O não atendimento das exigências pertinentes ao marco legal regulatório do Terceiro Setor pode implicar na limitação ou mesmo encerramento das atividades realizadas, o que pode produzir retrocessos para o público atendido. Nesse sentido, o presente artigo resulta de investigação que buscou responder o seguinte questionamento: como os elementos de gestão e do marco regulatório contribuem para a atuação de três associações da área da saúde pertencentes à RMVPLN em sua relação com a administração pública?

Perspectivas em Gestão \& Conhecimento, João Pessoa, v. 9, n. 3, p. 47-63, set./dez. 2019. 
A gestão social, ou seja, dos projetos sociais exige, por conta de suas peculiaridades, uma forma diferenciada de gestão e necessita, sobretudo, de um modelo que vá além daqueles adotados no primeiro e segundo setores (PRADO; NETO; CERONI, 2007). Necessariamente, essa conjuntura demanda por parte da direção da organização do Terceiro Setor uma gestão focada nas novas exigências oriundas da inovação legislativa expressa pelo marco regulatório.

O cenário característico às organizações do Terceiro Setor justifica o objetivo do presente artigo, que é o de compreender os elementos de gestão e do marco regulatório nas parcerias estabelecidas por três associações da área da saúde com as três maiores cidades paulistas da RMVPLN: São José dos Campos, Taubaté e Jacareí. Adota-se, para tanto, o critério de população e de Produto Interno Bruto (PIB) com a administração pública e a contribuição dessas parcerias para o Desenvolvimento Regional. O artigo é estruturado em seis seções, sendo a primeira esta introdução. A segunda seção trata dos pressupostos teóricos que fundamentaram a realização da pesquisa e a metodologia aplicada, a terceira descreve o método e o relaciona aos conceitos subjacentes à investigação, a quarta discute os resultados e realiza a sua análise e a quinta apresenta as considerações finais.

\section{TERCEIRO SETOR E O MARCO REGULATÓRIO}

A literatura norte-americana conceitua o Terceiro Setor como distinto do Estado e do mercado por dotar-se de características específicas, como a não distribuição de lucros, a independência e o voluntariado (CORRY, 2010). Nos Estados Unidos, quando há referência ao Terceiro Setor, adota-se ainda o termo "Sociedade Civil", percebido como independente e que se estabelece entre o estado, a igreja, a família e o mercado (MUUKKONEN, 2009). O que se verifica, contudo, é que não existe nos Estados Unidos uma pluralidade de conceitos acerca do Terceiro Setor, como no Brasil.

Para Falconer (1999), o Terceiro Setor brasileiro é estimulado a firmar parcerias com o Estado por intermédio da administração pública em todos os níveis, a partir de uma relação intersetorial que obscurece os limites entre os três setores. Já nos Estados Unidos, o Terceiro Setor nasce com a tentativa de demarcar a diferença e proclamar independência em relação aos demais setores. Oliveira (2005), em consonância com a literatura americana, conceitua o Terceiro Setor como independente, mas que pode firmar parcerias e receber investimentos públicos e privados. Pela perspectiva europeia observa-se que as entidades do Terceiro Setor combinam economia de mercado, redistribuição e reciprocidade e, por essa razão, não constituem um setor isolado, mas híbrido que atua entre mercado e Estado por almejar um benefício comunitário (DEFOURNY; NYSSENS, 2010). Para Moreira (1997), o Terceiro Setor é intermediário entre o Estado e as empresas mercadológicas, também híbrido do público e do privado, fruto da falta de comprometimento do Estado no que tange os serviços públicos. Denota-se, assim, que não há no Brasil consenso referente ao conceito do Terceiro Setor. Parte dos autores adere a linha americana e parte acompanha a literatura europeia.

A literatura americana representada por Claeyé (2014) ressalta que os gerentes das Organizações Não-governamentais (ONGs) não devem ser meros receptores passivos de conhecimento, ideias e práticas gerenciais que emanam da estrutura governamental. Eles precisam envolver-se ativamente por ideias e práticas, dentro de uma realidade cultural local. Segundo ele, o global e o local, ao interagirem, aumentam a eficácia da ajuda e desenvolvem melhores maneiras de gerenciar as ONGs.

Rodrigues (2013) entende que um dos grandes obstáculos encarados pelas organizações do Terceiro Setor concerne às formas de gestão, isso porque, uma vez inseridas em um ambiente político, econômico e social, elas ainda sofrem por conta das transformações da sociedade contemporânea. Já Albuquerque (2006) considera que a gestão de organizações

Perspectivas em Gestão \& Conhecimento, João Pessoa, v. 9, n. 3, p. 47-63, set./dez. 2019. 
do Terceiro Setor carece de boa gestão nos aspectos de recursos humanos, financeiros e materiais como estratégia para o bom andamento das atividades e cumprimento de seus objetivos, celebrando parcerias e atingindo a sustentabilidade.

Apura-se que, como nas entidades do segundo setor ou nos governos do primeiro setor, as instituições do Terceiro Setor devem abranger à gestão todas as espécies de recursos para atingir sua missão. Essas organizações são criadas e mantidas por pessoas que acreditam que mudanças são necessárias e que é preciso tomar providências nesse sentido. Por esse motivo, sua gestão difere das organizações do setor privado por não distribuírem lucros, bem como das organizações do setor público, pelo fato de não estarem sujeitas ao controle político direto, pois são independentes para determinar seu próprio andamento (HUDSON, 1999).

Nas organizações sem fins lucrativos existe, segundo Drucker (2006), dificuldade para a aplicação das técnicas de gestão por parte dos voluntários que nelas atuam, uma vez que estes consideram que gestão se relaciona à lucratividade. Johansen e Zhu (2013) afirmam que, pelo fato da concorrência no mercado, os gerentes privados priorizam a gestão da eficiência do serviço mais do que aqueles atuantes no Terceiro Setor. A gestão nas organizações sem fins lucrativos não pode repetir a mesma dinâmica de outras empresas, em razão de que o resultado deste processo não trata de uma mercadoria, mas de uma atuação no campo social (PRADO; NETO; CERONI, 2007). Por outro lado, para se ter um gestor que seja conhecedor das peculiaridades do Terceiro Setor é necessária uma formação superior que disponha de disciplinas voltadas à esta realidade.

A lei federal no 9.394/96, que estabelece as diretrizes e bases da educação nacional dispõe, em seu artigo 43, II, que a educação superior tem por finalidade formar diplomados nas diferentes áreas de conhecimento, aptos para a inserção em setores profissionais e para a participação no desenvolvimento da sociedade brasileira (BRASIL, 1996). O Ministério da Educação, através da Secretaria de Regulação e Supervisão da Educação Superior, diante das diversas solicitações de estudantes e Instituições de Educação Superior (IES) com pedidos de informações sobre a grade curricular dos cursos superiores, emitiu nota técnica n. 0 793/2015, de 12 de maio de 2015, que dispõe às IES a definição, de forma independente, de quais as disciplinas serão incluídas nas matrizes curriculares dos cursos, sem qualquer interferência por parte do Ministério da Educação (BRASIL, 2015).

Diante da norma, os componentes curriculares podem ser definidos de forma autônoma por cada IES, de modo a possibilitar o desenvolvimento de competências, habilidades, atitudes e práticas necessárias à formação integral do indivíduo, cidadão e profissional, visando à plena inserção deste na sociedade e no mundo do trabalho. Sobre as disposições curriculares das Instituições de Ensino Superior, Cuchiaro e Carizio (2011) afirmam que os currículos precisam ser formulados tendo em vista às necessidades regionais dos discentes e devem gerar aprendizagens suficientes para responder às carências sociais e profissionais em um determinado tempo e contexto. Portanto, cabe à instituição educacional garantir e organizar onde os participantes das disposições e das formações curriculares devem considerar o que está acontecendo na sociedade, assim como detectar as mudanças, as necessidades atuais da população, o mercado de trabalho e as novas exigências das carreiras profissionais (MASETTO, 2011). Desta forma, apura-se que a formação do gestor com disciplinas no ensino superior voltadas à administração do Terceiro Setor é fator contribuinte para o que os agentes sociais se tornem mais preparados para gerir projetos e ações sociais das organizações sem fins lucrativos.

Para uma maior profissionalização e transparência nas parcerias entre as entidades do Terceiro Setor e a administração pública foi aprovada a Lei Federal n. o 13.019, de 2004, conhecida como "Marco Regulatório", por meio da qual se comprova a urgência da gestão eficiente nas organizações sem fins lucrativos (BRASIL, 2014). Frente às mudanças nas maneiras de atuação da sociedade civil ocorridas nas últimas décadas, o Terceiro Setor

Perspectivas em Gestão \& Conhecimento, João Pessoa, v. 9, n. 3, p. 47-63, set./dez. 2019. 
consolida-se como área da aplicação das políticas públicas do país, uma vez que o Estado não detém a exclusividade da promoção do bem-estar social (SPALDING, 2016). Para a autora, com o avanço das entidades, constatou-se a carência legislativa referente a uma gestão de parcerias entre as organizações da sociedade civil e a administração pública. Daí estabelece-se, a partir desta análise, a premência da criação do marco regulatório do Terceiro Setor.

A legislação que representa o marco regulatório das organizações do Terceiro Setor foi necessária para sistematizar as relações entre o estado e as organizações da sociedade civil, pois estas promovem maior eficiência e flexibilidade na medida em que respondem às falhas do governo e mercado e são prestadoras de serviços à sociedade (MENDONÇA; SEGATTO, 2014). A totalidade da legislação passou a vigorar em todo o território brasileiro a partir de 10 de janeiro de 2017, sendo que o marco regulatório confere maior segurança jurídica ao Terceiro Setor, promovendo uma transparência na aplicação dos recursos e uma efetividade nas parcerias com a consequente valorização das entidades (SPALDING, 2016).

Em referência à modernização para uma gestão profissional das entidades do Terceiro Setor, Dora e Pannuzio (2013) analisam que a lei representou um avanço significativo à modernização do marco regulatório, reconhecendo como de interesse público não apenas as organizações que atuam em áreas tradicionais, como assistência social, educação e saúde, mas abarcando aquelas que atuam como temáticas mais contemporâneas, como às relacionadas ao meio ambiente ou direitos humanos.

\begin{abstract}
Além disso, estimulou a adoção de boas práticas de governança e gestão, abrindo caminho para uma administração mais profissional das organizações. Por fim, criou um novo instrumento para regular sua "contratualização" com o Estado - o "termo de parceria", dotado de mecanismos de controle e transparência mais adequados dos que os do antigo convênio e pautado por uma lógica de resultados que tende a melhor respeitar a autonomia do parceiro privado. (DORA e PANNUZIO, 2013, p. 12).
\end{abstract}

O marco regulatório das organizações da sociedade civil contribui para o processo de desenvolvimento das entidades do Terceiro Setor. Neste sentido, Lopes, Santos e Xavier (2014, p. 100) consideram que o marco "apresenta melhorias no sistema de prestação de contas dos projetos, diferenciados por volume de recursos e provendo os alicerces para que se faça 0 controle de resultados". Catalano $(2015$, p. 3$)$ destaca a nova forma para o repasse, a aplicação e o uso dos rendimentos, avaliando como inovadoras as regras a serem cumpridas para o repasse do fomento, sendo que "a aplicação dos valores e uso de seus rendimentos foram dispostas em lei, de forma clara e objetiva, assim como aquelas que devem ser cumpridas pelas entidades em sede de prestação de contas". Compreende-se, assim, que a nova legislação constitui instrumento que separa as organizações do Terceiro Setor éticas, transparentes e bem administradas daquelas vítimas da má administração e dos desvios de suas finalidades sociais, uma vez que torna mais rígidos os requisitos para a celebração de parcerias com a administração pública.

A administração pública encontra-se vinculada ao conceito de Estado "sobre o qual repousa toda a concepção moderna de organização e funcionamento dos serviços públicos a serem prestados aos administrados" (MEIRELLES, 2003, p. 58). Independentemente de sua atuação, o Estado deve, na concepção do autor, manter sempre sua única personalidade de direito público, constituído de três elementos originários e indissociáveis: povo, território e governo soberano. Moraes (1999), por sua vez, entende que a Constituição Federal vigente, diferentemente das anteriores, expõe um capítulo próprio para a organização da

Perspectivas em Gestão \& Conhecimento, João Pessoa, v. 9, n. 3, p. 47-63, set./dez. 2019. 
administração pública, destacando à particularização da estrutura governamental, sua função e princípios.

Na visão de Batista (2012), a administração pública é importante e complexa pelo fato de interferir em vários aspectos da sociedade, sendo que seu modo de atuar influencia a qualidade de vida, a viabilidade e o sucesso de uma sociedade. A expressão da administração pública possui, conforme Di Pietro (2003), dois sentidos em sua constituição. Em sentido subjetivo representa os entes que exercem a atividade administrativa e, em sentido objetivo, designa a natureza da atividade exercida pelos entes. Azevedo $(2008$, p. 17) assevera que a administração pública "é o conjunto de órgãos e entidades responsáveis por realizar, garantir, regulamentar e fiscalizar as atividades e ações necessárias à produção de bens e serviços focados no interesse público". Já Paludo (2010) diz que administração pública é a parte usada nas administrações direta e indireta nas esferas Municipal, Estadual e Federal. É uma função vinculada e intimamente ligada às escolhas e decisões do governo, seus poderes e órgãos.

Para melhor esclarecimento da temática, apontam-se no Quadro 1 as características da administração pública que a diferem da administração privada:

Quadro 1 - Diferenças entre Administração pública e privada

\begin{tabular}{|l|l|}
\hline \multicolumn{1}{|c|}{ Administração Pública } & \multicolumn{1}{|c|}{ Administração Privada } \\
\hline $\begin{array}{l}\text { O administrador deve executar apenas o que a } \\
\text { Lei o permite. }\end{array}$ & $\begin{array}{l}\text { O administrador pode fazer o que não estiver } \\
\text { proibido por Lei. }\end{array}$ \\
\hline $\begin{array}{l}\text { Almeja, em princípio, o desenvolvimento } \\
\text { social, de valores para a sociedade. }\end{array}$ & Almeja, em princípio, a obtenção de lucro. \\
\hline $\begin{array}{l}\text { Utiliza-se de recursos públicos, através da } \\
\text { arrecadação com a tributação. }\end{array}$ & Utiliza-se, via a regra, de recursos particulares. \\
\hline $\begin{array}{l}\text { O destinatário final, dos serviços e recursos, é } \\
\text { a sociedade de forma geral. }\end{array}$ & $\begin{array}{l}\text { O destinatário dos recursos e serviços é a própria } \\
\text { empresa e clientes. }\end{array}$ \\
\hline $\begin{array}{l}\text { Possui interesse público e deve administrar } \\
\text { para todos, de forma impessoal. }\end{array}$ & $\begin{array}{l}\text { Possui interesse particular e administra em função } \\
\text { de mercado e clientes. }\end{array}$ \\
\hline
\end{tabular}

Fonte: Autores (2019)

A administração privada e a administração pública apresentam distinções quanto às respectivas finalidades e possibilidades de gestão. A administrador público está circunscrito na sua atuação as possibilidades legais, enquanto no setor privado é possível realizar aquilo que não é legalmente proibido. Essa diferença reflete-se nas demais distinções entre o setor público e o setor privado, principalmente em razão das diferentes finalidades. No setor público a origem dos recursos ou tributos implica na necessidade de absoluta transparência para com a sociedade. No setor privado a origem particular dos recursos permite o foco na obtenção do resultado financeiro positivo, prioridade que articula a gestão privada. Inexiste, nos princípios de eficiência da administração privada o compromisso com o desenvolvimento social e econômico, exceto quando a organização realiza ações para contribuir para com a sociedade, porém, com a manutenção da obtenção do lucro para proprietários e acionistas como princípio fundamental.

A atuação do Estado e as ações realizadas a partir da administração pública ocorrem no território sob responsabilidade das autoridades no território. É no território que se materializam as condições que impelem ou dificultam o desenvolvimento, entendido enquanto melhoria das condições sociais e econômicas, o que sob a perspectiva do presente artigo é também consequência da atuação do Terceiro Setor. A compreensão do desenvolvimento inclui a dimensão regional, cujo recorte contribui para o entendimento adequado da atuação dos atores sociais distribuídos entre o Primeiro, o Segundo e o Terceiro Setor. Para o desenvolvimento regional, as relações e os comportamentos econômicos nas

Perspectivas em Gestão \& Conhecimento, João Pessoa, v. 9, n. 3, p. 47-63, set./dez. 2019. 
diversas sociedades não podem ser analisados só pelas questões econômicas, fruto da lucratividade e do sistema capitalista. Fatores sociais e ambientais nem sempre são conexos aos interesses econômicos, mas contribuem para o desenvolvimento (VIEIRA; SANTOS, 2012).

Somente a partir de laços comuns e de identidade fortalecidos no âmbito cultural, econômico e político que uma região será construída socialmente e, desta forma, existirá de fato para a sociedade. Para tal construção é necessário ainda aumentar a capacidade de autoorganização da região, transformando-a de segmentada e passiva em coesa e capaz de se mobilizar em torno de projetos políticos comuns, ou seja, capaz de se transformar em sujeito de seu próprio desenvolvimento (ETGES; DEGRANDI, 2013).

Mais do que um processo localizado de crescimento econômico e de mudança social que visa a melhoria da qualidade de vida material e imaterial de uma comunidade, Souza e Theis $(2009$, p. 12) conceituam Desenvolvimento Regional como um processo "socialmente equitativo e ecologicamente prudente, apoiado na democratização em todas as escalas, na participação ativa da cidadania na definição de seu paradigma societário, na completa soberania dos sujeitos na escolha de seu futuro". Neste sentido, as organizações da sociedade civil estão sendo cada vez mais estudadas como elementos deste desenvolvimento. Prova disso é "a investigação sobre as formas de atuação de organizações não-governamentais e associações da sociedade civil que têm sido consideradas na análise sobre o processo de desenvolvimento com maior frequência" (OLIVEIRA, 2007, p. 02).

Para Sen (2010, p. 29), "o desenvolvimento tem de estar relacionado, sobretudo, com a melhoria da vida que levamos e das liberdades que desfrutamos." $\mathrm{O}$ autor analisa que a sociedade atual vive em um mundo de privações e superá-las é uma parte do processo de desenvolvimento. Para que isso ocorra é mister a retirada das fontes de privação de liberdades representadas, por exemplo, pela pobreza, carência de oportunidades econômicas e, também, a negligência dos serviços públicos.

Vieira (2009) compartilha deste entendimento, frisando que o desenvolvimento vai além da oferta de bens e serviços oriundos da ampliação de produtividade. Nesta linha, Vieira e Santos (2012, p. 366) entendem o conceito de desenvolvimento como mais abrangente do que aquele que trata do crescimento econômico, uma vez que "enquanto o último demonstra uma variação na taxa de crescimento do PIB, o primeiro representa a melhoria das condições socioeconômicas dos indivíduos". Tem-se, portanto, o desafio de definir o que significa essa melhoria e quais critérios podem ser adotados para avaliá-la. Dessa forma, o desenvolvimento será constituído pela referência que determinada sociedade tem em relação ao crescimento da renda, da melhoria das condições sociais, de sustentabilidade e de processos sociais. Não cabe, pois, abordagem em somente única dimensão, mas num âmbito que as relacione de forma concomitante.

É oportuno salientar que a efetivação do desenvolvimento regional não decorre da aplicação de modelos econométricos, mas através de ações que colaborem com as políticas endógenas (VIEIRA; SANTOS, 2012). No tocante ao desenvolvimento endógeno, Souza e Theis (2009, p. 89) o consideram como sendo um "processo de desenvolvimento sustentável regional, onde passa a ser um processo contínuo de absorção do excedente gerado localmente". Os autores salientam que não se trata do isolamento de uma determinada região, mas uma reorganização interna da estrutura econômica, política e social que visa favorecer um ambiente propício à gestão do excedente. Verifica-se a possibilidade de sintonia dos objetivos de uma organização do Terceiro Setor com o processo de desenvolvimento, haja vista a realização de serviço público social em complementação aos serviços do Estado.

\section{MÉTODO}

Perspectivas em Gestão \& Conhecimento, João Pessoa, v. 9, n. 3, p. 47-63, set./dez. 2019. 
A presente pesquisa tem abordagem qualitativa com objetivo exploratório. Para a realização da investigação e identificação dos dados necessários à discussão da relação entre entidades do Terceiro Setor na área da saúde com o poder público no novo marco regulatório optou-se pelo exame de documentos relacionados às organizações estudadas e entrevistas com os respectivos gestores. Os critérios de escolha dos documentos são pertinentes às exigências legais quanto à inclusão de instituições como características do Terceiro Setor.

A análise dos documentos possibilitou perceber se as instituições selecionadas atendem aos critérios necessários à inclusão no Terceiro Setor e as exigências do marco regulatório. A partir dessa perspectiva procedeu-se a pesquisa documental em três organizações associativas da sociedade civil que mantém parcerias com a administração pública. Verificou sob esse prisma o estatuto, o regimento interno, a inscrição, certidões e situação cadastral das entidades junto à Receita Federal; certidões negativas de débitos federais, certificado de Entidade Beneficente de Assistência Social (CEBAS) e certidões do Fundo de Garantia por Tempo de Serviço (FGTS). E a realização das entrevistas propiciou o conhecimento sobre a atuação das instituições selecionadas para a realização da pesquisa. Possibilitou também a compreensão da relação para com poder público e das ações relacionadas à parceria e ao atendimento das metas estabelecidas.

Referente ao delineamento optou-se, também, pelo estudo de casos múltiplos ou de multicasos. Segundo Yin (2005), a pesquisa de caso pode incluir tanto os estudos de caso único quanto de casos múltiplos.

A primeira palavra de aconselhamento que se pode dar é que, embora todos os projetos possam levar a estudos de caso bem-sucedidos, quando você tiver escolha (e recursos), é melhor preferir projetos de casos múltiplos a projetos de caso único. Mesmo que você só possa fazer um estudo de caso de dois casos, suas chances de fazer um bom estudo de caso serão melhores do que usar projeto de caso único. Os projetos de caso único são vulneráveis no mínimo porque você terá apostado todas as suas fichas num único número. Mais importante do que isso, os benefícios analíticos de ter dois (ou mais) casos podem ser substanciais (YIN, 2005, p. 75).

Portanto, ao se estudar três associações da Região Metropolitana do Vale do Paraíba e Litoral Norte foi empreendido um estudo de casos múltiplos ou de multicaso. Compreende-se que, para a execução do estudo, a realização da pesquisa documental tornou-se fundamental para a melhor compreensão do caso, bem como para respaldar evidências coletadas por outros instrumentos e fontes, permitindo a confiabilidade de achados por meio de triangulação de dados e de resultados (MARTINS, 2008).

Foram cotejados, neste artigo, os conteúdos oriundos dos documentos pesquisados com os resultados das entrevistas realizadas, conforme disposto no item procedimentos de coleta de dados, avante exposto. Quanto à forma de pesquisa de campo, a abordagem executada foi por intermédio de entrevista semiestruturada aplicada nas instituições estudadas. Em cada entidade pesquisada foram realizadas três entrevistas (a primeira etapa durante o mês de julho de 2016, a segunda etapa no mês de setembro e a terceira etapa no mês de outubro do mesmo ano), totalizando-se nove entrevistas. Todas elas ocorreram dentro das sedes das respectivas instituições (São José dos Campos/SP, Taubaté/SP e Jacareí/SP).

A primeira fase das entrevistas foi composta por doze questões, a segunda fase contou com quatorze perguntas e a terceira e última dispôs de dez questões. As trinta e seis questões formuladas em cada associação foram constituídas por perguntas abertas e fechadas. Após as assinaturas dos competentes Termos de Consentimento Livre e Esclarecido por parte dos

Perspectivas em Gestão \& Conhecimento, João Pessoa, v. 9, n. 3, p. 47-63, set./dez. 2019. 
entrevistados, todas as entrevistas foram gravadas e transcritas, sendo que cada uma delas teve, em média, vinte minutos de duração.

Os dados obtidos por intermédio das entrevistas foram qualitativamente analisados por meio de um método repetitivo e reflexivo descrito por Souza (2009). Após a ocorrência das entrevistas realizou-se uma interpretação em conjunto, pelo qual foram estudadas eventuais inversões nos discursos dos entrevistados da mesma associação - fato que não ocorreu. Nesta fase, inicialmente, foi realizada a análise individual e, posteriormente, sintetizados os dados em um quadro comparativo para melhor visualização dos dados coletados.

Atendendo pedido das associações estudadas, não foram identificadas as organizações pesquisadas e os membros entrevistados, por questão de preservação no desenvolvimento do estudo. Rampazzo (2013) descreve que, neste tipo de entrevista, o entrevistador tem liberdade para adaptar perguntas à determinada situação. Assim, a discussão dos resultados foi tratada a partir da ótica da inovação legislativa do marco regulatório do Terceiro Setor referente às exigências para parcerias com a administração pública.

Os critérios de validação adotados para a escolha das cidades onde estão situadas às entidades pesquisadas foram o Produto Interno Bruto (PIB) total em Reais e a população, com embasamento nos dados da Fundação Sistema Estadual de Análise de Dados (SEADE), dos anos de 2014 e 2016, respectivamente. A escolha de entidades presentes nas três principais cidades da Região Metropolitana do Vale do Paraíba e Litoral Norte observou os critérios indicados em três associações privadas do mesmo segmento (atividades de atenção à saúde humana).

A tabela 1 revela as cinco maiores cidades da região conforme o PIB e a população, o que evidencia, segundo esses critérios, a seleção de São José dos Campos, Taubaté e Jacareí.

Tabela 1 - PIB total em Reais e população dos maiores municípios da Região Metropolitana do Vale do Paraíba e Litoral Norte (RMVPLN)

\begin{tabular}{|l|c|c|}
\hline \multicolumn{1}{|c|}{ Cidade } & PIB/ em 2014 & População/2016 \\
\hline São José dos Campos & $30.927 .049,98$ & 680.008 \\
\hline Taubaté & $15.436 .985,01$ & 296.449 \\
\hline Jacareí & $9.414 .192,52$ & 221.650 \\
\hline Pindamonhangaba & $6.227 .819,98$ & 157.459 \\
\hline Guaratinguetá & $4.471 .713,41$ & 116.020 \\
\hline
\end{tabular}

Fonte: SEADE (2016)

Os dados obtidos por intermédio das entrevistas foram qualitativamente analisados por intermédio método reflexivo adotado por Souza (2009). Partiu-se do pressuposto de que é preferível entrevistar um número reduzido de sujeitos, repetindo as entrevistas, do que entrevistar um número bem mais elevado, com questões estereotipadas (SOUZA, 2009). A repetição das entrevistas permitiu o reconhecimento das dinâmicas das instituições e a percepção das condições de relacionamento com o poder público. O método reflexivo ainda favoreceu a obtenção das informações com maior profundidade quanto à possibilidade de comparar os relatos de cada entrevistado em mais de uma ocasião.

\section{RESULTADOS E DISCUSSÃO}

A partir da metodologia descrita foi possível identificar os componentes da gestão atuantes nas parcerias com a administração pública das associações estudadas, bem como compreender a participação das parcerias no desenvolvimento regional. Em que pesem os entraves administrativos vividos pelas organizações do Terceiro Setor pesquisadas (haja vista que as organizações estudadas não atingem uma sustentabilidade financeira), reconhece-se que, com a vigência do marco regulatório, busca-se um aperfeiçoamento no planejamento, na

Perspectivas em Gestão \& Conhecimento, João Pessoa, v. 9, n. 3, p. 47-63, set./dez. 2019. 
execução e no controle das parcerias, fortalecendo a sociedade civil e promovendo o desenvolvimento regional.

Independentemente do âmbito da administração pública, parcerias com as organizações do Terceiro Setor devem seguir os requisitos exigidos pela Lei Federal n.․․ $13.019 / 2014$. Isso posto observou-se que todas as organizações estudadas se constituem juridicamente como associações privadas. De acordo com Lopes, Santos e Xavier (2014), o Brasil possui a maioria das entidades do Terceiro Setor nesta modalidade. Constatou-se, mediante as entrevistas, que as associações de São José dos Campos e de Jacareí têm parcerias vigentes nos três âmbitos da administração pública (municipal, estadual e federal), enquanto a associação de Taubaté apenas mantém parceria na esfera municipal.

Em atendimento ao objetivo deste artigo, verificou-se nos estudos multicasos que os elementos de gestão "legitimidade, capacidade de articulação, expansão das ações sociais, transparência e qualidade dos serviços" estão presentes nas parcerias das organizações estudadas com a administração pública. Vislumbrou-se, ainda, a busca destas organizações pela sustentabilidade e a disseminação de objetivos e identidades comuns. As entidades de São José dos Campos e de Jacareí possuem uma administração mais estruturada com relação à entidade de Taubaté, pois tem pessoal com maior qualificação, contratado especificamente para o gerenciamento dos recursos, e que participam e promovem mais projetos que movimentam maiores valores financeiros. Observa-se, assim, que a departamentalização das entidades com setor jurídico e profissional de contabilidade própria acena para uma gestão eficiente e organizada, o que, para Spalding (2016) supera o paradigma de que entidades do Terceiro Setor são instituições amadoras.

Quanto aos elementos do marco regulatório contidos nas parcerias vigentes entre as associações pesquisadas com a administração pública constatou-se relevância pública e social devido o cadastro ativo há mais de um ano, a experiência prévia na realização do objeto da parceria, as instalações, as condições materiais condizentes com as parcerias em vigor e a capacidade técnica e operacional referente ao objeto das parcerias. Apurou-se ainda que as instituições possuem método de gestão de parcerias sistemático. Todas as organizações, ao firmarem parcerias, realizaram projetos e atividades para cumprimento das suas respectivas finalidades estatutárias, e, portanto, para atividades de relevância pública e social. Contudo, uma associação, a de Taubaté, não tem setor ou departamento próprio para a gestão das parcerias, que compreendem desde o início do projeto e captação dos recursos/planejamento, com a organização e a execução, até o controle e avaliação final com a prestação e aprovação das contas, não cumprindo assim o que dispõem Prado, Neto e Ceroni (2007) sobre a gestão social, ou seja, dos projetos sociais que, por conta de suas peculiaridades, exigem uma forma diferenciada de gestão. Necessita-se, neste contexto, de um modelo além daqueles utilizados no primeiro e no segundo setor (PRADO; NETO; CERONI, 2007).

Todas as organizações estudadas mantêm um regimento interno e/ou Código de Ética, denotando-se que os empregados são norteados a atuarem pautados pelas missões e princípios das respectivas entidades, visando compromisso ético perante a sociedade, conforme dizeres de Prado, Neto e Ceroni (2007). Uma das peculiaridades da gestão de organização do Terceiro Setor é evidenciada no fato de os diretores das instituições pesquisadas, que possuem autonomia decisória e negocial, serem voluntários, diferenciandose dos demais dirigentes de empresas mercadológicas e entes públicos. Desta forma, a dinâmica da diretoria dessas associações mostra-se diferenciada a de outras empresas, como asseveram Prado, Neto e Ceroni (2007), com foco não em mercadorias, mas na esfera social.

A "departamentalização" das entidades estudadas, como a manutenção de setor jurídico e profissional de contabilidade própria, conforme Spalding (2016) demonstra uma gestão eficiente e organizada, o que supera o paradigma de que entidades do Terceiro Setor são instituições amadoras. Contudo, a associação de Taubaté revelou fragilidade quanto ao

Perspectivas em Gestão \& Conhecimento, João Pessoa, v. 9, n. 3, p. 47-63, set./dez. 2019. 
quesito relacionamento institucional, pelo fato de não possuir um setor/departamento específico para gestão de parcerias, inviabilizando uma célere e eficaz busca por verba vinda da administração pública, o que, na visão de Falconer (1999), pode aparentar uma deficiência.

As organizações do Terceiro Setor de São José dos Campos e de Jacareí possuem um setor específico para a captação de recursos, execução e desenvolvimento das parcerias com a administração pública, bem como sua devida prestação de contas. Dessa forma, as associações dessas duas cidades, além de adotarem um método sistemático e ordenado na gestão de parcerias, o realizam de forma "departamentalizada", contribuindo para o fortalecimento organizacional e a manutenção e viabilização de parcerias.

A estrutura das organizações atuantes em São José dos Campos e Jacareí possibilitou a ampliação das parcerias com o poder público em comparação a organização atuante em Taubaté, conforme indicado no Quadro 2:

Quadro 2 - Parcerias em vigência das associações de São José dos Campos, Jacareí e Taubaté

\begin{tabular}{|c|c|c|c|c|}
\hline Associação & Parceria em vigência & Início & Objeto & $\begin{array}{c}\text { Nível da } \\
\text { Administração } \\
\text { Pública }\end{array}$ \\
\hline \multirow[t]{4}{*}{$\begin{array}{l}\text { São José dos } \\
\text { Campos/SP }\end{array}$} & Ministério da Saúde & 2008 & $\begin{array}{c}\text { SUS (Sistema } \\
\text { Único de Saúde) }\end{array}$ & Federal \\
\hline & $\begin{array}{c}\text { Poder Executivo/Poder } \\
\text { Legislativo }\end{array}$ & & $\begin{array}{c}\text { Emendas } \\
\text { Parlamentares }\end{array}$ & Federal \\
\hline & $\begin{array}{c}\text { Poder Executivo/Poder } \\
\text { Legislativo }\end{array}$ & & $\begin{array}{c}\text { Emendas } \\
\text { Parlamentares }\end{array}$ & Estadual \\
\hline & Prefeitura Municipal & 2012 & Mutirão da Saúde & Municipal \\
\hline \multirow[t]{6}{*}{ Jacareí/SP } & Ministério da Saúde & 1989 & $\begin{array}{c}\text { SUS (Sistema } \\
\text { Único de Saúde) }\end{array}$ & Federal \\
\hline & Ministério da Saúde & 2001 & $\begin{array}{c}\text { - UCI (Unidade de } \\
\text { Cardiologia } \\
\text { Integrada) } \\
\text { - Oncologia } \\
\text { - Nefrologia }\end{array}$ & Federal \\
\hline & $\begin{array}{c}\text { Poder Executivo/Poder } \\
\text { Legislativo }\end{array}$ & 2016 & $\begin{array}{c}\text { Emendas } \\
\text { Parlamentares }\end{array}$ & Federal \\
\hline & $\begin{array}{c}\text { Poder Executivo/Poder } \\
\text { Legislativo }\end{array}$ & 2016 & $\begin{array}{c}\text { Emendas } \\
\text { Parlamentares }\end{array}$ & Estadual \\
\hline & $\begin{array}{l}\text { IAC (Incentivo de } \\
\text { Adesão à } \\
\text { Contratualização) }\end{array}$ & 2007 & Repasse & Estadual \\
\hline & Santa Casa & 1898 & Repasse & Municipal \\
\hline \multirow[t]{3}{*}{ Taubaté/SP } & Hospital Universitário & 2000 & Repasse & Municipal \\
\hline & $\begin{array}{c}\text { Santa Casa de } \\
\text { Pindamonhangaba }\end{array}$ & 2015 & Repasse & Municipal \\
\hline & Conselho Municipal & 2015 & Repasse & Municipal \\
\hline
\end{tabular}

Fonte: Dados da Pesquisa (2017)

Quanto à estrutura organizacional, denota-se que as associações de Taubaté e de São José dos Campos têm uma estrutura organizacional denominada linear, pois todas as áreas são estruturadas sob uma única linha de subordinação - a diretoria das entidades, existindo centralização das decisões e linhas formais de comunicação, conforme teoriza Picchiai (2010).

Perspectivas em Gestão \& Conhecimento, João Pessoa, v. 9, n. 3, p. 47-63, set./dez. 2019. 
Em ambas as organizações, a diretoria é órgão soberano e, somente através dela, ocorre a contração e a demissão de empregados. A estrutura organizacional linear é simples e econômica, com autoridade única e com unidade de comando facilitada. Tem o formato piramidal, com clara definição das atribuições e responsabilidades (PICCHIAI, 2010).

Já a organização do Terceiro Setor de Jacareí, conforme primeira entrevista realizada, revelou estrutura organizacional denominada funcional. Isso porque as gerências apresentam poderes negociais e decisórios dentro de sua esfera de atuação, na qual se pode contratar e demitir empregados sem a interferência da diretoria. Existe, nesta associação, uma chefia para cada função. Nesse tipo de estrutura organizacional ocorre a descentralização das decisões, com ênfase na supervisão especializada, sendo que os órgãos ou departamentos possuem o máximo de especialização (PICCHIAI, 2010).

As distinções administrativas entre as organizações contribuem para a compreensão das respectivas dinâmicas e formas de atuação. Entretanto, quanto à celebração de parcerias com a administração pública, é preciso atender aos requisitos legais conforme descrito parcialmente no Quadro 3:

Quadro 3: Requisitos para celebração de parceria com a administração pública

\begin{tabular}{|c|c|c|c|}
\hline Requisitos Legais & $\begin{array}{c}\text { Associação de São } \\
\text { José dos } \\
\text { Campos/SP }\end{array}$ & $\begin{array}{l}\text { Associação de } \\
\text { Jacareí/SP }\end{array}$ & Associação de Taubaté/SP \\
\hline $\begin{array}{l}\text { Objetivos de } \\
\text { relevância pública e } \\
\text { social. }\end{array}$ & $\begin{array}{l}\text { Artigo } 40 \text { do } \\
\text { Estatuto Social. }\end{array}$ & $\begin{array}{c}\text { Artigo } 2 \text { do Estatuto } \\
\text { Social. }\end{array}$ & Artigo $2^{\circ}$ do Estatuto Social. \\
\hline $\begin{array}{l}\text { Em caso de } \\
\text { dissolução, } \\
\text { transferência do } \\
\text { patrimônio. } \\
\end{array}$ & $\begin{array}{l}\text { Artigo } 40 \text { o do } \\
\text { Estatuto Social. }\end{array}$ & $\begin{array}{c}\text { Artigo } 24 \text { do Estatuto } \\
\text { Social. }\end{array}$ & $\begin{array}{l}\text { Artigo } 49 \text { o do Estatuto } \\
\text { Social. }\end{array}$ \\
\hline $\begin{array}{l}\text { Escrituração de } \\
\text { acordo com os } \\
\text { princípios } \\
\text { fundamentais de } \\
\text { contabilidade. }\end{array}$ & Não consta & $\begin{array}{c}\text { Artigo } 35 \text { do Estatuto } \\
\text { Social. }\end{array}$ & Não consta \\
\hline $\begin{array}{l}\text { Existência de, no } \\
\text { mínimo, um ano com } \\
\text { cadastro ativo. }\end{array}$ & $\begin{array}{c}\text { Cadastro ativo } \\
\text { desde } 28 / 08 / 2004 .\end{array}$ & $\begin{array}{c}\text { Cadastro ativo desde } \\
03 / 11 / 2005 .\end{array}$ & $\begin{array}{c}\text { Cadastro ativo desde } \\
24 / 09 / 2005 .\end{array}$ \\
\hline $\begin{array}{l}\text { Experiência prévia na } \\
\text { realização do objeto } \\
\text { da parceria. }\end{array}$ & Sim & Sim & Sim \\
\hline $\begin{array}{l}\text { Instalações, condições } \\
\text { materiais e } \\
\text { capacidade técnica e } \\
\text { operacional referente } \\
\text { ao objeto da parceria. }\end{array}$ & Sim & Sim & Sim \\
\hline
\end{tabular}

Fonte: Dados da Pesquisa (2017)

Afere-se, nos requisitos do marco regulatório do Terceiro Setor (Organizações da Sociedade Civil) - parcerias com a administração pública, de acordo com a Lei Federal n.으 13.019/2014, que as instituições pesquisadas estão aptas a firmarem ou renovarem parcerias com a administração pública. Há como unanimidade entre as instituições de que o maior desafio é a questão financeira, evidenciando-se assim a necessidade das parcerias com a administração pública e, consequentemente, uma eficiente gestão por parte das organizações do Terceiro Setor, o que notabiliza a relevância do estudo.

Perspectivas em Gestão \& Conhecimento, João Pessoa, v. 9, n. 3, p. 47-63, set./dez. 2019. 
As ações realizadas na área de saúde pelas associações pesquisadas, com seus respetivos projetos, configuram ações colaborativas com as políticas endógenas que contribuem para o desenvolvimento regional, não se utilizando para tal da aplicação de modelos econométricos, conforme Vieira e Santos (2012). A melhoria da qualidade de vida citada por Sen (2010) é constatada pelas finalidades das atividades executadas pelas organizações estudadas, que promovem a reabilitação da saúde, buscam a saúde integral, o resgate, restauro e a defesa da dignidade da vida humana. Ao empregarem, juntas, cerca de 1.130 trabalhadores devidamente registrados, as entidades de Terceiro Setor analisadas por este estudo comprovam capacidade de auto-organização e de fortalecimento para consecução de projetos significativos em prol do desenvolvimento regional.

\section{CONSIDERAÇÕES FINAIS}

A pesquisa acerca da gestão de parcerias entre organizações do Terceiro Setor e a administração pública evidenciou que as entidades que prestam serviços de benefício mútuo e público, sem fins lucrativos, vivem a maior mudança de toda a história legislativa, com o início de vigência do marco regulatório das organizações da sociedade civil. Dessa forma, essas organizações necessitam utilizar a gestão como instrumento para focarem seus objetivos e missão, na busca pelos resultados esperados. A legislação federal no 13.019/2014, que entrou em vigor de forma parcial em 23 de janeiro de 2016 e, de forma total, em 10 de janeiro de 2017 criou um regime jurídico para a formalização de parcerias entre a administração pública e as organizações da sociedade civil, prevendo no contexto citado regras mais claras e exigindo planejamento das partes envolvidas.

Apurou-se, durante a pesquisa, que embora sejam muitos os novos requisitos para a formalização de uma parceria com a administração pública, as associações estudadas demonstraram solidez administrativa, documental e de infraestrutura para o desenvolvimento de suas atividades. Todavia, verificou-se de forma exploratória que as organizações estudadas não atingem uma sustentabilidade financeira referente a valores financeiros fixos, capazes de suportar despesas ordinárias de folha de pagamento, com prestadores de serviços, manutenção de equipamentos e demais gastos, o que constitui requisito de gestão para o bom andamento dos recursos humanos e materiais.

Constatou-se que, nas instituições estudadas, devido a configuração da organização interna departamental e documental, o marco regulatório ainda não foi impactado de modo a afetar as parcerias em vigência ou projetos que almejam novas parcerias. Porém, verificou-se a preocupação das associações quanto às novas formalidades legais e a lentidão natural que pode gerar às futuras parcerias em face das inúmeras exigências, que buscam transparência e efetividade por parte da Lei n. 0 13.019/2014. Nenhuma das organizações pesquisadas tomou iniciativa para superar a referida lentidão, como a ampliação de pessoal técnico operacional, especificamente para antecipar as novas exigências legais, ou capacitação dos colaboradores ou voluntários envolvidos nos procedimentos para as novas parcerias com a administração pública, conforme a transição gerada pelo marco regulatório do Terceiro Setor.

Ao se detectar, nas nove entrevistas realizadas, bem como na pesquisa documental, que as organizações estudadas prestam serviços de benefício público na área da saúde, atingindo pessoas das mais diversas cidades da Região Metropolitana do Vale do Paraíba e do Litoral Norte, verificou-se também a contribuição delas para o desenvolvimento regional. Isso porque as associações complementam a atuação Estatal na esfera social, sobretudo na área da saúde, quando atendem indistinta e gratuitamente a sociedade civil e ainda empregam formalmente mais de mil colaboradores. Denotou-se, ainda, que as organizações pesquisadas se consolidam como respectivos membros da aplicação das políticas públicas da Região

Perspectivas em Gestão \& Conhecimento, João Pessoa, v. 9, n. 3, p. 47-63, set./dez. 2019. 
Metropolitana do Vale do Paraíba e Litoral Norte, do qual o Estado (quer seja municipal, estadual ou federal) já não é mais visto como exclusivo na promoção do bem-estar social.

Entretanto, os estudos multicasos mostraram que, embora as organizações pesquisadas sejam referência em suas respectivas peculiaridades dentro da esfera da saúde, ainda são dependentes do primeiro setor (Estado) no tocante à verba pública, por meio de parcerias. Na análise das parcerias que as associações têm com a administração pública, restou como fato conclusivo que os elementos da gestão como legitimidade, capacidade de articulação, expansão das ações sociais, transparência e qualidade dos serviços fortalecem a relação com o estado e com a sociedade civil.

Notou-se ainda que as parcerias apreciadas fortalecem as organizações do Terceiro Setor e os usuários dos serviços sociais prestados, condição que também contribui para o desenvolvimento regional. A entidade de Jacareí, dentre as estudadas, é a que possui o maior número de parcerias vigentes com a administração pública, sendo também a maior associação empregadora e com maior estrutura física e tecnológica, exceto, para o tratamento de crianças e adolescentes com câncer. Neste caso destaca-se a associação de São José dos Campos, que possui uma melhor estrutura, haja vista sua finalidade social.

O fato de as organizações estudadas de São José dos Campos e Jacareí serem possuidoras do CEBAS concedido pelo Governo Federal viabiliza uma maior probabilidade de celebração de parcerias com a administração pública. O mesmo não ocorre com a entidade de Taubaté, que está ainda em processo para obtenção deste certificado.

Conclui-se, assim, que o processo de parcerias com a administração pública exige organização administrativa pontual, documental e de estrutura física, além de uma ilibação por parte dos dirigentes das organizações do Terceiro Setor, o que não ocorria anteriormente à vigência do marco regulatório das parcerias efetivadas com a administração pública, conforme a Lei Federal n.o 13.019/2014. Tal condição não é, porém, definitiva, fato que apresenta-se como limitador e que, por consequência, merece ser acompanhado por pesquisas futuras.

\section{REFERÊNCIAS}

ALBUQUeRQUE, A. C. C. de. Terceiro setor: história e gestão de organizações. São Paulo: Summus, 2006.

AZEVEDO, L. O. A., Gestão administrativa no mundo dos concursos: administração pública, administração financeira e orçamentária. Brasília: LP, 2008.

BRASIL. Lei $\mathrm{n} .0$ 9.394, de 20 de dezembro de 1996. Estabelece as diretrizes e bases da educação nacional. Disponível em http://www.planalto.gov.br/ccivil 03/Leis/L9394.htm. Acesso em: 06 mai. 2016.

BRASIL. Lei 13.1019 de 31 de julho de 2014. Diário Oficial [da] República Federativa do Brasil, Brasília, n 146, p. 01, 1 ago. 2014, seção 1.

BRASIL. Nota Técnica n.o 793/2015, de 12 de maio de 2015. Grade curricular de cursos de Educação Superior. Ministério da Educação, Secretaria de Regulação e Supervisão da Educação Superior, Diretoria de Política Regulatória. Disponível em http://portal.mec.gov.br/index.php?option=com docman\&view=download\&alias=17472-ntn793-2015-grade-curricular\&category slug=maio-2015-pdf\&ltemid=30192. Acesso em: 06 mai.2016.

Perspectivas em Gestão \& Conhecimento, João Pessoa, v. 9, n. 3, p. 47-63, set./dez. 2019. 
BATISTA, F. F. Modelo de gestão do conhecimento para a administração pública brasileira: como implementar a gestão do conhecimento para produzir resultados em benefício do cidadão. Brasília: Ipea, 2012.

CATALANO, K. R. C. O marco regulatório das organizações da sociedade civil: avanços e retrocessos na atividade administrativa de fomento. Revista de Direito do Terceiro Setor [recurso eletrônico], Belo Horizonte, v. 9, n. 17, jan./jun. 2015. Disponível em: http://dspace/xmlui/bitstream/item/20014/PDlexibepdf.pdf?sequence=1. Acesso em: 05 jul. 2015.

CLAEYÉ, F. Managing Nongovernmental Organizations: Culture, Power and Resistance. New York: Routledge, 2014.

CORRY, O. Defining and theorizing he third sector. In: TAYLOR, R. (ed.) Third Sector Research. New York, Dordrecht, Heidelberg, London: Springer, 2010.

CUCHIARO, A. L.; CARIZIO, W. G. Ensino superior, currículo e formação profissional. Revista Fafibe On-line, 2011. Disponível em: http://www.unifafibe.com.br/revistasonline/arquivos/revistafafibeonline/sumario/9/1805201 1155059.pdf. Acesso em: 02 mai. 2016.

DEFOURNY, J.; NYSSENS, M. Social enterprise in Europe: At the crossroads of market, public policies and third sector. In: Policy \& Society, v. 29, no. 3, p. 231-242 2010.

DI PIETRO, M. S. Z. Direito administrativo. 15 ed. São Paulo: Atlas, 2003.

DORA, D.; PANNUNZIO, E. Comentários sobre o anteprojeto de lei apresentado pelo grupo de trabalho marco regulatório das organizações da sociedade civil. São Paulo: FGV, 2013.

DRUCKER, P. F. Administração de organizações sem fins lucrativos: princípios e práticas. Tradução de Nivaldo Montigelli Júnior. São Paulo: Pioneira Thomson Learning, 2006.

ETGES, V. E.; DEGRANDI, J. O. Desenvolvimento regional: a diversidade regional como potencialidade. Revista Brasileira de Desenvolvimento Regional, Blumenau, 1 (1), p. 85-94, outubro de 2013.

FALCONER, A. P. A promessa do terceiro setor: um estudo sobre a construção do papel das organizações sem fins lucrativos e do seu campo de gestão. Dissertação (Mestrado em Administração) - Programa de Pós-Graduação da Faculdade de Economia, Administração e Contabilidade da Universidade de São Paulo, São Paulo: 1999.

HUDSON, M. Administrando organizações do terceiro setor. São Paulo: Makron Books, 1999.

JOHANSEN, M.; ZHU, L. Market competition, political constraint, and managerial practice in public, non-profit, and private American hospitals. Journal of Public Administration Researchand Theory, 2013.

LOPES, L. de F.; SANTOS, B. dos.; XAVIER, I. R. Marco regulatório das organizações da sociedade civil: a construção da agenda no governo federal - 2011 a 2014. Brasília: Governo Federal, 2014.

Perspectivas em Gestão \& Conhecimento, João Pessoa, v. 9, n. 3, p. 47-63, set./dez. 2019. 
MARTINS, G. de A. Estudo de caso: uma estratégia de pesquisa. 2. ed. São Paulo: Atlas, 2008.

MASETTO, Marcos Tarciso. Inovação curricular no ensino superior. Revista Científica ecurriculum. ISSN 1809-3876, v. 7, n. 2, 2011 . Disponível em http://revistas.pucsp.br/index.php/curriculum/article/view/6852. Acesso em: 04 mai. 2016.

MEIRELLES, H. L. Direito administrativo brasileiro. 28. ed. São Paulo: Malheiros, 2003.

MELLO, O. A. B. de. Princípios gerais de direito administrativo. Rio de Janeiro: Forense, 1979.

MENDONÇA, P. M. E. de.; SEGATTO, C. I. Reflexões sobre a relação entre as Organizações da Sociedade Civil (OSCs) e o Estado: marco legal, mecanismos de financiamento e implicações para a gestão. ENANPAD, 38., Rio de Janeiro/RJ, 13 a 17 de setembro de 2014. Disponível em: http://www.anpad.org.br/admin/pdf/2014 EnANPAD APB1018.pdf. Acesso em 28 jun.2016.

MORAES, A. de. Direito Constitucional. 6. ed. São Paulo: Atlas, 1999.

MOREIRA, Vital. Auto regulação profissional e administração pública. Coimbra: Almedina, 1997.

MUUKKONEN, M. Civil society and related concepts. Nonprofit and Voluntary Sector Quarterly, v. 38, n. 4, p. 684-700, 2009.

OLIVEIRA, E. A. de A. Q. Economia dos clusters industriais e desenvolvimento. Revista Brasileira de Gestão e Desenvolvimento Regional, Taubaté, v. 3, n. 3, p. 247-259, set./dez. 2007. Disponível em: http://www.rbgdr.net/revista/index.php/rbgdr/article/view/96/89. Acesso em: 02 jul. 2015.

OLIVEIRA, G. H. J. de. Estado contratual, direito ao desenvolvimento e parceria públicoprivada. In: TALAMINI, Eduardo et al. (Coord). Parceria público-privada: uma abordagem multidisciplinar. São Paulo: RT, 2005. p. 83-119.

PAES, J. E. S. Fundações e entidades de interesse social: aspectos jurídicos, administrativos, contábeis e tributários. Brasília: Brasília Jurídica, 1999.

PALUDO, A. V. Administração pública: teoria e questões. Rio de Janeiro: Elsevier, 2010.

PICCHIAI, D. Estruturas organizacionais modelos. Universidade Federal de São Paulo, 2010. Disponível em: http://dgi.unifesp.br/seplan/templates/docs/seplanmodelos de estruturas organizacionais material.pdf. Acesso em: 07 jul. 2016.

PRADO, C. R.; NETO, J. C. S; CERONI, M. R. Filantropia, ética e gestão nas ONGs. São Paulo: Expressão e Arte, 2007.

RAMPAZZO, L. Metodologia científica: para alunos dos cursos de graduação e pós-graduação. 7. ed. São Paulo: Loyola, 2013.

RODRIGUES, J. L. K. Gestão do empreendimento social. Rio de Janeiro: Publit, 2013. 
SÃO PAULO. Lei 1.166 de 09 de janeiro de 2012. Cria a Região Metropolitana do Vale do Paraíba e Litoral Norte. Diário Oficial do Estado de São Paulo, São Paulo, p. 01, jan. 2012, seção 1.

SEADE - Fundação Sistema Estadual de Análise de Dados. Disponível em: http://www.imp.seade.gov.br/frontend/\#/tabelas2014. Acesso em: 11 abr. 2016.

SEADE - Fundação Sistema Estadual de Análise de Dados. Disponível em: http://www.imp.seade.gov.br/frontend/\#/tabelas2016. Acesso em: 16 jan. 2017.

SEN, A. Desenvolvimento como liberdade. Tradução de Laura Teixeira Motta e revisão técnica Ricardo Doninelli Mendes. São Paulo: Companhia das Letras, 2010.

SOUZA, C. M. de M.; THEIS, I. M. Desenvolvimento regional: abordagens contemporâneas. Blumenau: Edifurb, 2009.

SOUZA, J. A ralé brasileira: quem é e como vive. Belo Horizonte: UFMG, 2009.

SPALDING, E. Os fundos patrimoniais endowment no Brasil. 133 f. Dissertação de Mestrado Escola de Direito de São Paulo da Fundação Getúlio Vargas, São Paulo, 2016.

TACHIZAWA, T. Organizações não governamentais e terceiro setor: criação de ONGs e estratégias de atuação. 5. ed. São Paulo: Atlas, 2012.

VIEIRA, E. T. Industrialização e políticas de desenvolvimento regional: o vale do Paraíba paulista na segunda metade do século XX. 177 f. Tese de Doutorado - Faculdade de Filosofia, Letras e Ciências Humanas, Universidade de São Paulo, 2009.

VIEIRA, E. T.; SANTOS, M. J. Desenvolvimento econômico regional - uma revisão histórica e teórica. Revista G\&DR, v. 8, n. 2, p. 344-369, mai-ago/2012, Taubaté, SP.

VIOLIN, T. C. Terceiro setor e as parcerias com a Administração Pública: uma análise crítica. 2. ed. Belo Horizonte: Fórum, 2010.

YIN, R. K. Estudo de caso: planejamento e métodos. Tradução de Daniel Grassi. 2. ed. Porto Alegre: Bookman, 2005.

Artigo recebido em 06/08/2018 e aceito para publicação em 05/12/2019 